\title{
Neuroticism and Introversion: The Personality Predispositions to develop Depression
}

\author{
Saba Riaz ${ }^{1}$, Fatima Khurram Bukhari ${ }^{2}$, Arif Nadeem ${ }^{3}$
}

\begin{abstract}
The previous research studies claimed that there is a relationship between personality predispositions and affective disorders like depression. Personality traits like neuroticism and introversion are considered as a vulnerable factors for the development of depression. Therefore, the aim of this research study was to investigate that whether personality traits like introversion and neuroticisms are linked to depression. The researcher recruited a sample size of 200 university students who were studying in Islamia University Bahawalpur, Bahauddin Zakariya University Multan, and Women University Bahawalpur. Beck depression inventory (BDI), Introversion scale and Neuroticism dimension included in an inventory which was used to measure depression, introversion and neuroticism respectively. Statistical analysis included descriptive statistics, Pearson's correlation, regression analysis and an independent sample t-tests. The results revealed that there was a positive significant relationship between neuroticism, introversion personality traits and depression. The introversion and neuroticism personality traits significantly predicted depression.
\end{abstract}

Key Words: Neuroticism, Introversion, Depression, Pearson's Correlation, Regression Analysis Received: 09 May 2021; Revised Received: 11 September 2021; Accepted: 06 November 2021

${ }^{1} \mathrm{MS}$ Scholar, Department of Psychology, Lahore Garrison University, Lahore, Pakistan.

${ }^{2}$ Assistant Professor, Department of Applied Psychology, The Islamia University of Bahawalpur, Pakistan.

${ }^{3}$ Lecturer, Department of Applied Psychology, Government College University, Faisalabad, Pakistan. depression than others (Daniel et al., 2011). The disturbance of mood along with the symptomology like sad mood, loss of an ability to gain pleasure, irritability, and sleep disturbance both in quantity and quality, disturbance in appetite, less self-worth, suicidal thoughts must be present for 2 weeks to meet the criteria of depression (Minirth, 2004). Neuroticism and low extroversion (introversion) personality traits are strongly associated with depression (Janowsky, 2001).

Neuroticism is a personality trait which indicates the tendencies of a person to avoid Corresponding Author Email:

sabariazqureshi@gmail.com

\section{Introduction}

According to the predisposition model, personality traits are different from psychopathology and plays a causal role in the development of psychopathology. Personality traits are present before the developmental onset of depressive disorder and the individuals who possess certain personality traits are more prone to develop a harm (Cloninger, 1987) and being nervousness (PT \& Jr, 1987). Generally, neuroticism manifests itself as a form of negative feelings like anger, anxiety, embarrassment (Karanci et al., 2007) along with loneliness, fear and worry (Asendorpf \& Neyer, 2012) and individuals who are high in neuroticism personality trait are more prone to react to issues, emotional instability, insecure, impulsive and more vulnerable to psychological distress (Karanci et al., 2007).

This article is distributed under the terms of the Creative Commons Attribution Non Commercial 4.0 License (http://www.creativecommons.org/licenses/by-nc/4.0/) which permits nonCommercial use, reproduction and distribution of the work without further permission provided the original work is attributed as specified. 
Beside neuroticism personality trait, people who scores low on extraversion (Introversion) are shy (Gudjonsson et al., 2004) often seen as reserved, quiet, responsible and are controlled by their emotions. Introverts regain their energy by spending time alone (Tieger \& BarronTieger, 2001). Introverts tends to enjoy their own company and they like to interact with a smaller group of people (Kroeger \& Thuesen, 1992) which shows their tendency of developing a relatively few intimate relationships but for long time as compared to the people who score high on extroversion trait. Introverts tends to be aroused more than extroverts and when they experience stress, they are more likely to withdraw, act passively, less verbally responsive and irritable (Laney, 2005). Introverts are more prone to develop feelings of inadequacy and discontent whenever they have to cope in an extraverted society which make them more vulnerable to develop feelings of low selfesteem and depression (Chioqueta \& Stiles, 2005).

Introversion and depression are strongly interlinked which means that individuals who are introvert may prone to development of depressive symptomology (Fruyt et al., 2006). This may be due to the fact that introversion personality is comprised of a trait such as self-dislike, introspection and sensitivity which makes an individual more prone to depression (Chioqueta \& Stiles, 2005). The linkage between introversion and depression may be explained by looking into certain traits of introversion like introspective, feeling and sensitive personality type, and self-dislike traits like introspective nature (Van Gundy \& Schieman, 2001). Sensitive personality type (Janowsky, 2001) and self-dislike (Bums, 1999) are positively related to depression which all reveal the connection between introversion and depression. Similarly, according to the studies relating neuroticism and depression, neuroticism is strong predictor of developing depression (Duggan, et al., 1995) and its characteristics are useful to study the genetics of depression because there is comparatively equal heritability of both neuroticism which is $40-50 \%$ (Lake et al., 2000) and depression which is $36 \%$ (Kendler \& Prescott, 1999). Beside this, the sharing of same genetic risk factors is the cause of the correlation between neuroticism and depression of almost $70 \%$ (Kendler et al., 1993). Depression in adults is linked with many risk factors in which one of the risk factor is a personality trait known as neuroticism. Among the adult population the association between neuroticism and depression is $15-20 \%$ which indicates that elder people are experiencing high level of neuroticism (Nordfjaern et al., 2013). The prevalence of depression in females with respect to males is twice and the female gender in Asian and Western countries are consistently reported to experience greater depressive symptomology (Besser \& Shackelford, 2007). The gender differences in depression is partially mediated by high probability of females as compared to males of experiencing stress. The personality traits, neuroticism and introversion are high in females than males and which is suggested to be a possible explanation of gender differences regarding depression (Goodwin $\&$ Gotlib, 2004). Females who scores high in these personality dimension are more likely to experience depression in their adolescence (Kercher et al., 2009).

The research studies exploring the vulnerability to depression of introverts more than extroverts shows mixed findings. For example, the findings of one study reveals that the vulnerability to depression is not measured by extroversion (Farmer et al., 2002) while other study concluded that there is no relationship between introversion and depression (Duggan et al., 1995). A study hypothesized a weak relationship between 
introversion and depression (Kendler et al., 2006). According to the previous literature, neuroticism significantly predicts depression and those who score high in neuroticism has a greater probability of developing depression (Kotov et al., 2010). The study conducted by Lönnqvist et al. (2009) stated that affective disorders are highly predicted in young adulthood at the time when personality has stabilized (Lönnqvist et al., 2009). Others conclude that neuroticism is a strong vulnerability marker to develop depression (Lang \& Farmer, 2007). However, the adversity of childhood enhance the probability of a girls to score high on neuroticism and depression scales (Rosenman \& Rodgers, 2006) as compared to boys who score low on introversion ( high extroversion) (Barrio et al., 1997).

Therefore, this study had the following objectives:

$>$ To determine the relationship between neuroticism, introversion personality traits and depression.

$>$ To examine that whether personality predispositions such as neuroticism and introversion predict depression.

$>$ To assess that whether male and female gender varies on personality traits like neuroticism, introversion and depression.

\section{Method}

The research design used in this study was a quantitative cross-sectional design. The dependent variable was depression and the independent variables were introversion and neuroticism personality traits. The participants were recruited online for this study through a convenient sampling technique and were university students with a sample size of 200 which includes gender distribution of males with a sample size of 75 and females with sample size of 125 with a mean age of $(M=22.70, S D=3.93)$. Beck depression inventory (BDI), introversion scale and neuroticism dimension of International personality item pool (IPIP) were administered to measure depression, introversion and neuroticism respectively. BDI is a 21 item inventory which measures depression. The higher score on BDI indicates more depression. The chronbach alpha of BDI for this study was 0.85 (Beck et al., 1988). Introversion scale is an eighteenitem scale to measure introversion personality traits (Richmond \& McKroskey, 1998). The average score on this scale is 19 and the higher score indicates more introversion personality trait. The Chronbach alpha of introversion scale for this study was 0.76 . The neuroticism was measured by a 20 neuroticism dimension items included in the international personality item pool (IPIP, 2019). Higher score indicates more neuroticism. The chronbach alpha of neuroticism dimension scale for this study was 0.77 .

The statistical analysis was performed by using SPSS v 23. The researcher used descriptive statistics, Pearson's correlation, regression analysis and independent sample t-tests. Descriptive statistics was used to draw a general summary of all the collected data. Pearson's correlation was used to determine the relationship between neuroticism, introversion personality traits and depression. Similarly, an independent sample t-test was used to investigate that whether there was a gender difference between males and females in terms of neuroticism, introversion personality predispositions and depression. 


\section{Results}

\section{Table 1}

Descriptive Statistics of Age, Depression, Neuroticism and Introversion $(n=200)$

\begin{tabular}{lll} 
Variables & \multicolumn{1}{c}{$\boldsymbol{M} \boldsymbol{S}$} \\
\hline Participant's age (in years) & 22.83 & 3.59 \\
Depression & 10.84 & 8.48 \\
Introversion & 14.59 & 6.02 \\
Neuroticism & 54.05 & 11.16 \\
\hline
\end{tabular}

Note: $M=$ mean, $S D=$ standard deviation

The baseline characteristics of the participants are indicated in Table 1.

Table 2

Correlations between Neuroticism, Introversion and Depression $(n=200)$

\begin{tabular}{llllll}
\hline Variables & $\boldsymbol{M}$ & $\boldsymbol{S D}$ & $\mathbf{1}$ & $\mathbf{2}$ & $\mathbf{3}$ \\
\hline 1.Depression & 10.84 & 8.48 & - & & \\
2.Introversion & 14.59 & 6.02 & $.34^{* *}$ & - & \\
3.Neuroticism & 54.06 & 11.16 & $.56^{* *}$ & $.41^{* *}$ & - \\
\hline
\end{tabular}

Note: $M=$ mean, $S D=$ standard deviation

$* p<0.05, * * p<.01$

Pearson's correlation analysis among correlation between introversion and neuroticism, introversion personality traits depression $(\mathrm{r}(198)=.34, p<.01)$. The and depression indicate a significant positive participants who scored higher on either relationship between neuroticism and neuroticism or introversion personality traits depression $(\mathrm{r}(198)=.561, p<.01)$. Similarly, were at a greater risk for developing there was also a significant positive depression

Table 3

Multiple Linear Regression of Neuroticism, Introversion and Depression ( $n=200)$

\begin{tabular}{|c|c|c|c|c|c|c|c|}
\hline Predictors & $\mathbf{R}^{2}$ & $F(d f)$ & Sig. & $\beta$ & SE & $\mathbf{t}$ & Sig \\
\hline Introversion & .330 & 48.25 & .000 & .13 & .09 & 2.12 & .03 \\
\hline Neuroticism & & $(2,198)$ & & .50 & .04 & 7.87 & .01 \\
\hline
\end{tabular}

Outcome=Depression

Multiple linear regression analysis was carried out which revealed that introversion and neuroticism personality traits significantly predicted depression $(t=2.12$, $p<.05),(t=7.87, p<.05)$ respectively, having a variance of $\left(\mathrm{R}^{2}=0.33\right)$. The participants who scored higher on either neuroticism or introversion personality traits were at $33 \%$ risk of developing depression. 
Table 4

Independent Sample t-test for Gender Differences in Neuroticism, Introversion and Depression $(n=200)$

\begin{tabular}{lccccccc} 
Gender & \multicolumn{2}{c}{ Male $^{\mathrm{a}}$} & \multicolumn{2}{c}{ Female $^{\mathrm{b}}$} & & \\
Variables & $\boldsymbol{M}$ & $\boldsymbol{S D}$ & $\boldsymbol{M}$ & $\boldsymbol{S D}$ & $\boldsymbol{t}(\boldsymbol{d} \boldsymbol{f})$ & $\boldsymbol{p}$ & \\
\cline { 2 - 7 } & & & & & & & Cohen's d \\
\hline Introversion & 13.78 & 6.68 & 14.87 & 5.48 & $-1.18(127.98)$ & 0.23 & 0.17 \\
Neuroticism & 53.41 & 10.68 & 55.06 & 10.18 & $-1.07(144.59)$ & 0.28 & 0.15 \\
Depression & 10.72 & 8.63 & 10.25 & 8.18 & $0.37(143.97)$ & 0.70 & 0.05 \\
\hline
\end{tabular}

Note. $N=200, M=$ mean, $S D=$ Standard deviation

$\mathrm{n}^{\mathrm{a}}=75, \mathrm{n}^{\mathrm{b}}=125$

$* p<0.05, * * p<0.01$

An independent sample $t$-test indicated that there were no significant gender differences in the scores of introversions between male $(M=13.78, S D=6.68)$ and females $(M=14.87$, $S D=5.48), \quad t(127.98)=-1.18, \quad p>.05)$. Similarly, there was no significant differences in the scores of neuroticisms between males $(M=53.41, S D=10.68)$ and females $(M=55.06, S D=10.18), t(144.59)=$ -

\section{Discussion}

The present research is investigating the personality traits neuroticism and depression as a vulnerable predisposition for developing depression. Our research finding indicated that there was significant positive correlation between the neuroticism, introversion personality traits and depression. The finding of our research study is also consistent with the findings of studies conducted by (Chioqueta \& Stiles, 2005; Fruyt et al., 2006; Nordfjaern et al., 2013) who founded that there was a positive significant relationship between neuroticism, introversion and depression.

The other findings of our research study revealed that personality traits, neuroticism and introversion were a significant predictor of depression. The results of our research study are also supported by the previous research studies like the studies conducted by (Duggan et al., 1995; Farmer, et al., 2002;
$1.07, p>.05$. There was no significant difference in the score of depression between males $(M=10.72, S D=8.63)$ and females $(M=10.25, S D=8.18), \quad t(143.97)=0.37$, $p>.05)$. Both male and female participants were at equal risk for developing depression due to neuroticism and introversion personality trait.

Kotov et al., 2010; Lang \& Farmer, 2007; Lönnqvist et al., 2009). These studies founded that neuroticism and introversion predicted the development of depression.

The other findings of our result shows that there are not significant gender differences regarding the introversion, neuroticism personality traits and depression. Our study contradicts the findings of the study conducted by (Rosenman \& Rodgers, 2006) who founded that neuroticism and introversion personality traits were higher in females. Our research finding is also contradict the finding of the study which shows that female report more neuroticism and depressive symptoms (Kercher et al., 2009). The contradiction between this result finding and other was the result of methodological error which is online conduction of study and the difference in the 
number of participant gender wise which is 125 females and 75 males.

\section{Limitations and Suggestions}

The primary strength of the study is that it revealed a significant positive relationship between neuroticism, introversion personality traits and depression. The prediction of these personality traits is helpful for clinicians who treat depression. There is a risk factor that these type of personalities (neuroticism, introversion) may lead to depression. So, identification of these personality traits through research is a big strength of this study and has clinical implications.

The limitations of this study include online data collection which may lead to response set exhibited by participants without knowing the purpose of research. Since the participants are not directly provided by the researcher to answer them if they have any type of ambiguities regarding research. The second limitation includes the recruitment of non-clinical sample due to COVID-19 pandemic which lags behind research findings as comparative of the studies which shows that clinical sample having depression scores high on introversion than non-clinical sample.

Future studies may include the role of mediating and moderating variables while study depression as a result of personality traits. Some moderators such as gender, life stress and mediators may include interpersonal conflicts, maladaptive coping strategies. The longitudinal studies are required because personality traits are not static and change over a course of one's development.

\section{Conclusion and Implications}

This research study aimed to investigate a relationship between personality traits such as neuroticism, introversion and depression. A quantitative cross-sectional research design was used to collect data from participants. By using statistical techniques such as Pearson correlation, regression analysis and t-test, this study revealed that there was a positive significant relationship between neuroticism, introversion and depression. This study also found that both neuroticism and introversion predicted up to $33 \%$ the risk of developing depression in individuals. There was no significant gender variation in participants in terms of neuroticism, introversion and depression.

This research study has some therapeutic implications. Therapists must evaluate the personality predispositions of depressed patients when the patients are not responsive to the traditional pharmacotherapy including Selective Serotonin Reuptake Inhibitors and Selective Norepinephrine Reuptake Inhibitors for treatment of depression. This research study have also implications for the prevention of depression. A meta-analysis evidence indicated that through personality researches, some clinical implications prevented $25 \%$ depression in patients (Cuijpers et al., 2008).

\section{Conflict of Interest}

There is no conflict of interest declared by authors.

\section{Source of Funding}

The authors declared no source of funding.

\section{References}

Asendorpf, J., \& Neyer, F. (2012). Psychologie der Persönlichkeit [Psychology of personality] (5th ed.). Berlin, Germany: Springer.

Barrio, V. d., Moreno-Rosset, C., Rosa, L.M., \& Margarita, O. (1997). Anxiety, depression and personality structure . Person. Individual Differences, 23, 112.

Beck, A. T., Steer, R.A., \& Garbin, M.G. (1988) Psychometric properties of the Beck Depression Inventory: Twentyfive years of evaluation. Clinical Psychology Review, 8(1), 77-100. 
Besser, A., \& Shackelford, T. (2007). Mediation of the effects of the big five personality dimensions on negative mood and confirmed affective expectations by perceived situational stress: A quasi-field study of vacationers. Personality and Individual Differences, 42, 13331346.

Bums, D. (1999). Feeling good. New York, NY: Avon Books, Inc.

Chioqueta, A., \& Stiles, T. (2005). Personality traits and the development of depression, hopelessness, and suicide ideation. Personality and Individual Differences, 38(6), 1283-1291.

Cloninger, C. (1987). A systematic method for clinical description and classification of personality variants. Archives of General Psychiatry , 44(6), 573-588.

Cuijpers, P., van, S., F, S., Mihalopoulos, C., \& Beekman, A. (2008). Preventing the onset of depressive disorders: a meta-analytic review of psychological interventions. American Journal of Psychiatry, 165,1272-1280.

Daniel, N., Roman, K., \& Sara, J. (2011). Personality and Depression: Explanatory Models and Review of the Evidence. Annual Review of Clinical Psychology, 1-12.

Duggan, C., Sham, P., Lee, A., Minne, C., \& Murray, R. (1995). Neuroticism: A vulnerability marker for depression evidence from a family study. Journal of Affective disorders, 35(3), 139-143.

Farmer, A., Redman, K., Harris, T., Mahmood, A., Sadler, S., Pickering, A., \& McGuffin, P. (2002). Neuroticism, extraversion, life events and depression: The Cardiff
Depression Study. British Journal of Psychiatry, 181, 118-122.

Fruyt, D., F.D, Van, L., Bagby, R., Rolland, J., \& Rouillon, R. (2006). Assessing and interpreting personality change and continuity in patients treated for major depression. Psychological Assessment, 18(1), 71-80.

Goodwin, R., \& Gotlib, H. (2004). Gender differences in depression: the role of personality factors. Psychiatry Research, 126(2), 135-142.

Gudjonsson, G., Sigurdsson, J., Bragason, O., Einarsson, E., \& Valdimarsdottir, E. (2004). Compliance and personality: The vulnerability of the unstable introvert. European Journal of Personality, 18(5), 435-443.

International Personality Item Pool (2019). https://ipip.ori.org/

Janowsky, D. (2001). Introversion and extraversion: Implications for depression and suicidality. Current Psychiatry Report, 3(6), 444-450.

Karanci, A., Darik, G., \& Yorulumez, O. (2007). Reliability and validity studies of Turkish translation of Eysenck Personality Questionnaire Revised-abbreviated. Turk Psikyiatri Derg, 18(3), 254-261.

Kendler, K., Gatz, M., Gardner, C., \& Pedersen, N. (2006). Personality and major depression: A Swedish longitudinal, population-based twin study. Archieves of General Psychiatry, 63(10), 113-1120.

Kendler, K., Neale, M., Kessler, R., Heath, A., \& Eaves, L. (1993). A longitudinal twin study of personality and major depression in women. 1993). Archives of General Psychiatry, 50, 853-862.

Kendler, K., \& Prescott, C. (1999). A population-based twin study of lifetime major depression in men and 
women. Archives of General Psychiatry, 56, 39-44.

Kercher, A., Rapee, R., \& Schniering, C. (2009). Neuroticism life events and negative thoughts in the development of depression in adolescent girls. Journal of Abnormal Child Psychology, 37(7), 903-915.

Kotov, R., Gamez, W., Schmidt, F., \& Watson, D. (2010). Linking "big" personality traits to anxiety, depressive, and substance use disorders: a meta-analysis. Psychological Bulletin, 136(5), 768821.

Kroeger, O., \& Thuesen, J. (1992). Type talk at work: How the 16 personality types determine your success on the job. New York, NY: Tilden Press.

Lake, R., Eaves, L., Maes, H., Heath, A., \& Martin, N. (2000). Further evidence against the environmental transmission of individual differences in neuroticism from a collaborative study of 45,850 twins and relatives on two continents. Behavioral Genetics, $30,223-233$.

Laney, M. (2005). The hidden gifts of the introverted child. New York, NY: Workman Publishing Company, Inc.

Lang, K., \& Farmer, A. (2007). The causes of depression. In: Stein G, Wilkinson G (Eds)Seminars in general adult psychiatry. London: The Cromwell Press, 48-70.

Lönnqvist, J., Verkasalo, M., Mäkinen, S., \& Henriksson, M. (2009). High neuroticism at age 20 predicts history of mental disorders and low selfesteem at age 35. Journal of Clinical Psychology, 65,781-790.

Minirth, F. (2004). Choices that can change your life. Grand Rapids, MI: Fleming $\mathrm{H}$. Revell. In pursuit of happiness, 112.
Nordfjaern, T., Bjerkeset, O., Moylan, S., \& Berk, M. (2013). Cluster of personality traits and psychological symptoms associated with later benzodiazipines prescriptions in the general population:the HUNT cohort study. Addictive Behaviors, 25752580.

PT, C., \& Jr, M. (1987). Neuroticism, somatic complaints, and disease: Is the bark worse than the bite? Journal of Personality, 55(2), 299-316.

Richmond, V. P., \& McCroskey, J. C. (1998). Communication apprehension, avoidance and effectiveness (5th Ed.). Boston: Allyn \& Bacon.

Rosenman, J., \& Rodgers, B. (2006). Childhood Adversity and Adult Personality. Journal of Psychiatry, 40(5), 1-12. https://doi.org/10.1080/j.14401614.2006.01826.x

Tieger, P., \& Barron-Tieger, B. (2001). Do what you are: Discover the perfect career for you through the secrets of personality type (3rd ed.). Boston, MA: Little, Brown \& Company.

Van Gundy, K., \& Schieman, S. (2001). Looking inward: Introspectiveness, physical disability, and depression across the life course. International Journal of Aging and Human Development, 53(4), 293-310. 